NBER WORKING PAPER SERIES

\title{
CAN AT SCALE DRUG PROVISION IMPROVE THE HEALTH OF THE TARGETED IN SUB-SAHARAN AFRICA?
}

\author{
Adrienne M. Lucas \\ Nicholas L. Wilson \\ Working Paper 23403 \\ http://www.nber.org/papers/w23403 \\ NATIONAL BUREAU OF ECONOMIC RESEARCH \\ 1050 Massachusetts Avenue \\ Cambridge, MA 02138 \\ May 2017
}

We would like to thank Herby Derenoncourt, Albert Mwango, Frank Sloan, Jeffrey Stringer, Harsha Thirumurthy, Jenny Trinitapoli, two anonymous referees, and seminar participants at Harvard University, the International Health Economics Association (iHEA) 11th Annual Congress, Northeastern University, the Northwest Development Workshop, the Population Association of America Annual Meeting, Swarthmore College, and the University of Washington for many excellent comments. Madeleine Watson and Wentao Xiong provided superb research assistance. The NBER Africa Project provided generous financial and institutional support. The NBER Africa Project was not involved in study design, data collection/analysis, manuscript writing, and the decision to submit the manuscript for publication. This research would not be possible without the assistance of the Network of Zambian People Living with HIV/AIDS (NZP + ), the Zambia Central Statistical Office, and the Zambia Ministry of Health. All errors are our own. The findings, interpretations, and conclusions expressed in this paper are those of the authors and do not necessarily represent the views of the aforementioned individuals or agencies, nor of the National Bureau of Economic Research.

NBER working papers are circulated for discussion and comment purposes. They have not been peer-reviewed or been subject to the review by the NBER Board of Directors that accompanies official NBER publications.

(C) 2017 by Adrienne M. Lucas and Nicholas L. Wilson. All rights reserved. Short sections of text, not to exceed two paragraphs, may be quoted without explicit permission provided that full credit, including $\odot$ notice, is given to the source. 
Can at Scale Drug Provision Improve the Health of the Targeted in Sub-Saharan Africa?

Adrienne M. Lucas and Nicholas L. Wilson

NBER Working Paper No. 23403

May 2017

JEL No. H51,I12,I15,I18,O12,O15

\section{ABSTRACT}

The single largest item in the United States foreign aid health budget is antiretroviral therapy (ART) for the treatment of HIV/AIDS. Many supply- and demand-side factors in sub-Saharan Africa could cause smaller than expected epidemiological effects of this at scale drug provision. We provide what appears to be the first quasi-experimental evidence on the effect of at scale drug provision in a poor country, using the phased roll-out of ART in Zambia, a setting where approximately 1 in 6 adults are HIV positive. Combining anthropometric data from national household surveys and a spatially-based triple difference specification, we find that local ART introduction increased the weight of high HIV likelihood adult women. This finding from a clinically difficult setting suggest that the generalized challenges of scalability of ART for adult health in sub-Saharan Africa are surmountable.

Adrienne M. Lucas

Lerner College of Business and Economics

University of Delaware

419 Purnell Hall

Newark, DE 19716

and NBER

alucas@udel.edu

Nicholas L. Wilson

Department of Economics

Reed College

3203 SE Woodstock Blvd

Portland, OR 97202

nicholas.l.wilson@gmail.com 


\section{Introduction}

The single largest item in the United States' foreign aid health budget is antiretroviral therapy (ART) for the treatment of HIV/AIDS (Moss 2008, Government Accountability Office 2010). The United States President's Emergency Plan for AIDS Relief (PEPFAR) has funded the rapid nationwide scale-up of heavily subsidized ART distribution in much of sub-Saharan Africa (UNAIDS 2010), a region of the world where HIV/AIDS causes nearly one-third of mortality among those aged 15-59 (WHO 2011). Despite the central focus of global health policy on drug provision in sub-Saharan Africa, little quasi-experimental evidence exists about the total epidemiological effects of drug provision at scale on the targeted in this setting. ${ }^{1}$ In this study we focus on Zambia, a country with one of the highest HIV/AIDS prevalence rates in the world, and estimate the effect of the at scale provision of ART on the health of likely HIV positive women.

Even with large expenditures that have financed the rapid scale-up of heavily subsidized nationwide ART distribution in much of sub-Saharan Africa, many challenges remain that could lessen ART's effectiveness. Low overall health spending (WHO 2006a), inadequate infrastructure (WHO 2006a), high patient-health worker caseloads (WHO 2006a), weak incentives (Basinga et al. 2011), health worker absenteeism (Goldstein et al. 2012), and counterfeit drugs (Bate et al. 2011, Björkman-Nyqvist et al. 2012) have led to weak health systems (De Cock et al. 2011) that could inhibit ART effectiveness at scale. Further, demand side barriers such as incomplete adherence could further impede success (Mills et al. 2014).

We conduct our study in Zambia, a particularly interesting context for at least two reasons. First, Zambia has one of the highest HIV prevalence rates in the world with roughly 1 in 6 adults in the country being HIV positive (Central Statistical Office et al. 2009). Second, Zambia was one

\footnotetext{
${ }^{1}$ To the best of our knowledge, Jayachandran et al. (2010), which examines the effect of sulfa drugs on health in the United States using a difference-in-differences regression approach, is the only other quasi-experimental evidence on the effects of drug provision at scale in any setting.
} 
of the fifteen original PEPFAR focus countries and under PEPFAR I received substantial external support for ART provision and little support for the broader health sector.

In order to identify the effects of at scale ART provision on health, we use a difference-indifference-in-differences (i.e. triple difference) strategy. We combine typical spatial and temporal variation from the geographic location of all health facilities and the date when these facilities first distributed ART with a third difference, an individual's likely HIV status. This triple difference specification allows us to identify the effect of the availability of ART net of any time invariant or time varying differences across regions.

Our data provide compelling evidence for a highly relevant question, but our HIV data are unfortunately not ideal. National surveys at the height of the epidemic, our pre-ART availability period, that include HIV testing are rare. Given the sensitivity of the question prior to the availability of ART and the desire to respect the confidentiality of respondents, the HIV test results cannot be linked to individual respondents of the first round of our household survey that was completed in 2001. Instead individual test results were anonymized at the age group, gender, urban or rural, province cell. Data anonymized using this method are the only data from this era that can be spatially linked to ART proximity in a high HIV prevalence country. We create a binary HIV approximation based on the cell level averages. Additional information on our HIV measure appear in the Data Section. Our empirical strategy appears to be the best feasible strategy for estimating the effect of ART expansion on the health of the targeted during the height of the epidemic.

In order to address concerns related to our measurement of HIV status, we conduct two checks of our main estimates. One check relaxes the binary HIV specification of the main analysis to use the full, continuous measure as a likelihood of being HIV positive. A second check calibrates our estimates using results from efficacy studies of ART and body mass from other low-income settings.

We use respondent weight as a proxy for overall health status and respondent height as a placebo 
outcome. HIV positive women clinically eligible for ART experience substantial weight loss due to the development of HIV into AIDS. Evidence from efficacy studies conducted in various developing countries found weight gains of 2.6 to $10.3 \mathrm{~kg}$ after six to twelve months of treatment (Médecins sans Frontiéres South Africa et al. 2003, Koenig et al. 2004, Severe et al. 2005, Saghayam et al. 2008, Koethe et al. 2010, Thirumurthy and Graff Zivin 2012). Due to data availability, our analysis is limited to women age 15-49.

Our empirical framework allows us to compare the changes in anthropometrics associated with the timing of local ART introduction for high HIV likelihood and low HIV likelihood individuals residing near and far from health facilities where ART was introduced. Our overall effect will include both direct and indirect effects of local ART introduction on high HIV likelihood women.

Our results indicate that local ART introduction improved the health of the targeted. We find that ART introduction within 10 kilometers $(\mathrm{km})$ of the respondent increased the weight of high HIV likelihood women by approximately 1.6 kilograms $(\mathrm{kg})$, or approximately one-sixth of a standard deviation. While this point estimate is smaller than some clinic-based studies that focused only on HIV positive women, we approximate the effect on directly treated women of over $10 \mathrm{~kg}$. Consistent with a causal interpretation of this main result, semi-parametric triple-difference evidence indicates that our findings are not the result of a differential pre-introduction trend. We also find evidence that the increase in weight was concentrated among women living within $10 \mathrm{~km}$ of health facilities that distributed ART, and that local ART introduction did not affect height, a health outcome that should not be affected by receiving ART, further reinforcing a causal interpretation of our main result.

The estimated weight gain suggests a highly successful ART scale-up despite the many logistical and behavioral barriers that are often cited as limiting large public health campaigns in Africa (WHO 2006, De Cock et al. 2011, Fauci and Marsten 2013). 
Our paper makes a number of important contributions. First, we provide the first quasiexperimental evidence on the effect of the at-scale provision of adult ART. Second, to the best of our knowledge, this paper provides the first quasi-experimental evidence on the effects of drug provision at scale on adult morbidity in sub-Saharan Africa, complementing quasi-experimental evidence on the effects of sulfa drugs in the United States (Jayachandran et al. 2010). Third, we have demonstrated that targeted health campaigns in sub-Saharan Africa can be successful despite health sector barriers.

More broadly, this paper contributes to the quasi-experimental literature in economics on the health effects of large, targeted government-run public health programs in poor countries (e.g., Miller et al. 2013, Gruber et al. 2014) and elsewhere (e.g., Finkelstein 2007, Card et al. 2008, Almond et al. 2009, Hoynes and Schanzenbach 2009, Card et al. 2009, Hoynes et al. 2011, Finkelstein et al. 2012). Further, this paper contributes to the quasi-experimental literature on the health effects of HIV/AIDS spending in Africa (e.g., Bendavid et al. 2012), the non-experimental literature on the direct health effects of ART provision at scale (e.g., Paella et al. 1998, Bor et al. 2013), the quasi-experimental literature on the indirect health effects of ART provision at scale (Lucas and Wilson 2013, Baranov et al. 2015), and the quasi-experimental literature on the behavioral effects of ART (e.g., Thirumurthy et al. 2008, Graff Zivin et al. 2009, McLaren 2010, de Walque et al. 2012, Thirumurthy and Graff Zivin 2012, Friedman 2013, Baranov et al. 2015, and Lucas and Wilson 2015).

Among existing quasi-experimental literature on HIV/AIDS spending, our paper is most closely related to Bendavid et al. (2012), yet differs in two key ways. First, we isolate the effects of ART availability on the health of the targeted instead of the effect of PEPFAR funding on all-cause adult mortality, the approach of Bendavid et al. (2012). While PEPFAR was not designed to strengthen health sectors broadly, the increase in spending could have increased aggregate demand or had 
other effects across adults regardless of HIV status. ${ }^{2}$ These effects are, by design, included in their estimates, while we focus only on the health of the targeted, those who were HIV positive. Second, our triple-difference specification controls for both time varying and time invariant differences between locations that did and did not receive ART. Bendavid et al. (2012) use a difference-indifferences approach that relies on the standard parallel trends assumption and cannot control for time varying differences between PEPFAR and non-PEPFAR countries or regions within a country with high or low PEPFAR take up. Therefore, we are answering a different question using a methodology that can better control for potential time varying heterogeneity.

The paper is organized as follows. Section 2 briefly describes antiretroviral therapy in subSaharan Africa. Section 3 explains the empirical strategy we use to identify the epidemiological effects of ART scale-up on the targeted. Section 4 describes the household survey and health facilities census data. Section 5 presents the results. Section 6 concludes.

\section{Antiretroviral Therapy in Sub-Saharan Africa}

The development of antiretroviral therapies has been called "one of the greatest...breakthroughs" in the fight against HIV/AIDS (Barre-Sinoussi 2011). Antiretroviral drugs reduce the viral load and increase the general health of individuals living in the advanced stages of HIV (WHO 2006b).

Expanding access to antiretroviral therapy (ART) for HIV positive individuals throughout much of sub-Saharan Africa has been a central component of U.S. foreign aid since the mid-2000s, shifting the focus away from cash transfers, investment in economic infrastructure, training, technical expertise, and small grants toward commodities (Tarnoff and Larson 2011). At the time of our study, ART was the largest item in the United States foreign aid health budget and PEPFAR was the

\footnotetext{
${ }^{2}$ In Zambia, the focus of our study, between 2000 and 2008, HIV development assistance increased from US\$10 million to US $\$ 250$ million (Ooman et al. 2007, Reisch et al. 2008), an increase from approximately US $\$ 1$ per capita to US $\$ 25$ per capita. This represented a substantial fiscal stimulus for a country with GDP per capita in 2007 of US\$770 (World Bank 2009).
} 
largest source of HIV/AIDS funding worldwide (Schneider and Garrett 2009). PEPFAR's initial funding targeted 15 focus countries, mostly in sub-Saharan Africa, to receive large-scale financial support. More than one-half of PEPFAR I spending was allocated to ART and care for ART patients (Moss 2008). While annual U.S. spending on HIV/AIDS in international health increased from US $\$ 204$ million in 2001 to US $\$ 3.3$ billion in 2008, annual U.S. spending on non-HIV international health only increased from US\$1.3 billion to US\$1.7 billion (Government Accountability Office 2010).

Zambia, the location for the current study, is a PEPFAR focus country having received between US\$1 billion and US\$1.4 billion for HIV/AIDS through PEPFAR by 2013 (Fan et al. 2013a, PEPFAR 2013). The Global Fund to Fight AIDS, Tuberculosis and Malaria, the second largest HIV/AIDS donor in Zambia, has disbursed between US $\$ 270$ million and US $\$ 500$ million for HIV/AIDS (Fan et al. 2013b, Global Fund to Fight AIDS, Tuberculosis and Malaria 2012). Other smaller donors are also operating in Zambia, combining to provide the final one-third to one-half of HIV/AIDS donor funding in Zambia (Oomman et al. 2007, Resch et al. 2008).

Prior to the authorization of PEPFAR in 2004, ART was virtually unavailable in Zambia. By 2007, the end of the period that we examine in this analysis, approximately one in five health facilities provided ART and nearly one-half of the Zambian population lived within $10 \mathrm{~km}$ of an ART site. ${ }^{3}$ In addition to providing ART, these clinics provided nutrition counseling to ART patients (Koethe et al. 2010). Thus, our estimates of the effect of local ART introduction on high HIV likelihood adult female health will be the combined effect of ART provided in conjunction with nutrition counseling. ${ }^{4}$

\footnotetext{
${ }^{3}$ In Section 4, we describe the data we use to make these calculations.

${ }^{4}$ While this counseling likely enhanced the efficacy of ART, it was not substantial enough alone to account for our estimates of weight gain due to local ART introduction but could contribute to our relatively large estimates. Nutrition counseling frequently accompanies ART distribution.
} 


\section{Empirical Strategy}

Our primary empirical strategy is a difference-in-difference-in-differences (i.e. triple difference) specification. We exploit spatial and temporal variation in exposure to ART expansion between two national household surveys (i.e. the 2001 and 2007 Demographic Health Surveys (DHS)), as well as variation across individuals in the likelihood of being HIV positive. ${ }^{5}$

Intuitively, our triple difference strategy creates a treatment group of women with high HIV likelihood who live near a health facility where ART was introduced by 2007 and who are surveyed in 2007. Women who satisfy none or only some of these conditions (e.g., women with high HIV likelihood who live hear a health facility where ART was introduced by 2007 but were surveyed in 2001) act as the control group. This method alleviates concerns about differential trends between HIV positive and negative women as well as about differential trends for locations that did and did not have clinics where ART was introduced prior to 2007. Empirically, this process is completed in a single triple difference specification:

$$
\begin{aligned}
\text { health }_{i j t}= & \alpha_{0}+\beta A R T_{j} \times \text { Year } 2007_{t} \times H I V_{i j t} \\
& +\alpha_{1} A R T_{j}+\alpha_{2} \text { Year } 2007_{t}+\alpha_{3} H I V_{i j t} \\
& +\alpha_{4} A R T_{j} \times Y \text { ear } 2007_{t}+\alpha_{5} A R T_{j} \times H I V_{i j t}+\alpha_{6} Y \text { ear } 2007_{t} \times H I V_{i j t} \\
& +Z_{i j t}^{\prime} \Gamma+\eta_{\text {district }}+\delta_{m}+\varepsilon_{i j t}
\end{aligned}
$$

where health $h_{i j t}$ denotes the anthropometrics of female respondent $i$ residing in Statistical Enumeration Area (SEA) $j$ and interviewed in month-year combination $t, A R T_{j}$ is an indicator variable equal to one if a health facility located near respondent $i$ offered ART twelve months prior to the

\footnotetext{
${ }^{5}$ We describe how we measure the likelihood of being HIV positive in Section 4.
} 
2007 survey (i.e. an "ever ART" measure), Year2007t is an indicator variable equal to one if the respondent was surveyed in $2007, H I V_{i j t}$ is a binary measure that captures the respondent's likelihood of being HIV positive, $Z_{i j t}^{\prime}$ is a vector of individual and household level demographic controls (i.e. indicator variables for five year age group, primary school completion, secondary school completion, urban residence, urban residence interacted with Year $2007_{t}$, local PMTCT availability, local VCT availability, and district fixed effects interacted with the $Y e a r 2007_{t}$ indicator variable ${ }^{6}$ ), $\delta_{m}$ are fixed effects for interview month, $\eta_{\text {district }}$ are district fixed effects, and $\epsilon_{i j t}$ is an idiosyncratic error term, allowed to be correlated within a SEA, the level at which local ART availability varies in our data. ${ }^{7}$ We estimate all specifications using ordinary least squares (OLS) regressions. As our specifications control for time varying differences between locations through the use of a set of district dummy variables interacted with Year2007t as well as concurrent HIV programs and lower level interactions of the triple difference regressor of interest, we interpret $\beta$ as the causal effect of local ART introduction on the anthropometrics of HIV positive adult females. ${ }^{8}$

In the baseline specification, we consider respondents within $10 \mathrm{~km}$ of a health facility that provided ART as having ART locally available. As a specification check we test for a spatial gradient and find $10 \mathrm{~km}$ to be a reasonable catchment approximation.

\section{Data}

To undertake our analysis, we use repeated cross-sectional geo-referenced national household surveys and a unique geo-referenced HIV/AIDS services panel.

\footnotetext{
${ }^{6}$ We include additional controls in the Robustness Section.

${ }^{7}$ Because we have more than 300 SEAs in each of the two DHS surveys, standard asymptotic tests are appropriate (Cameron et al. 2008).

${ }^{8}$ Our triple-difference strategy identifies the effect of local ART on high HIV likelihood adult females net of any local ART effects shared by high HIV likelihood and low HIV likelihood adult females.
} 


\subsection{Individual-level data}

Our individual survey data are the 2001 and 2007 Zambia Demographic Health Surveys (DHS), cross-sectional national household surveys. These data contain adult female anthropometrics, basic demographic and socioeconomic information, geographic location, and HIV testing results. We use respondent weight as a proxy for overall health status and respondent height as a placebo outcome. While in a middle- or high-income country context the weight concern is often obesity, the opposite is true in Zambia. Women are more likely to be below healthy weight than overweight. Mean BMI in our 2001 sample is just over 21, not far from the minimum of the normal range of the BMI guidelines from US National Institutes of Health. Further, HIV positive individuals clinically eligible for ART experience substantial weight loss due to the development of HIV into AIDS. As documented in efficacy studies from various developing countries (Médecins sans Frontiéres South Africa et al. 2003, Koenig et al. 2004, Severe et al. 2005, Saghayam et al. 2008, Koethe et al. 2010, Thirumurthy and Graff Zivin 2012), individuals clinically eligible for ART typically experience noticeable weight gain within six to twelve months of treatment, reversing much of the weight loss due to the development of HIV into AIDS.

Only women aged 15 to 49 at the time of the survey were both tested for HIV and weighed and measured. Therefore, we limit our sample to these individuals. For each respondent we calculate the approximate latitude and longitude of their dwelling from details on the location of the primary sampling unit centroids. ${ }^{9}$

Both the 2001 and 2007 Zambia DHS included HIV testing modules. Two issues guided the construction of the HIV measure, the individual's likely HIV status, that we use in the empirical

\footnotetext{
${ }^{9}$ Some geographic imprecision is unavoidable with these data, potentially introducing attenuation bias. For the 2001 DHS, we use a digitized census map provided by the Zambia Central Statistical Office to locate the SEA centroid. Unfortunately, approximately $7 \%$ of SEAs were missing from the maps used for the 2001 data, resulting in the removal of respondents from these areas in our sample. The 2007 DHS provides approximate GPS locations for each SEA centroid. The exact coordinates are offset by adding a random vector with length drawn from a uniform distribution on 0 to $10 \mathrm{~km}$ to maintain respondent privacy.
} 
specifications. First, due to privacy concerns, the 2001 HIV data were anonymized and cannot be linked with individuals in the household rosters. Instead for each individual tested, the result is accompanied by the individual's gender, age, urban/rural status, and province of residence. Second, the response rate for the HIV testing module was roughly $75 \%$ in each of the survey rounds. Therefore, we assign each individual a likelihood of being HIV positive measured as the HIV prevalence in the respondent's demographic group defined as the interaction of survey round, gender, five year age group, urban/rural status, and province of residence. ${ }^{10}$ Median HIV prevalence in the 2001 and 2007 Zambia DHS using this measure is 0.14 , the tenth percentile is 0.03 , and the ninetieth percentile is 0.35 . Our primary regression specifications use an indicator variable to denote likely HIV status, equal to one if the respondent is in a demographic group with HIV prevalence at or above the median. This helps address concerns that HIV prevalence in a demographic group in our sample rarely exceeds 0.5 , for example, yet approximately 1 in 6 individuals in our sample are HIV positive. As a robustness check, we also use a continuous measure of HIV prevalence in the demographic group.

\subsection{Health facilities data}

Our health facilities data were originally collected for Wilson (2015). In 2006, the Japanese International Cooperation Agency (JICA) Health Facility Census (HFC) recorded the latitude and longitude of each health facility in Zambia. To augment these data, we surveyed these clinics starting in 2008 to collect information on the month and year (if any) they began offering each of the three main HIV/AIDS services: ART, voluntary counseling and testing (VCT), and preventing mother to child transmission (PMTCT). This augmented HFC contains comprehensive information on the expansion of HIV/AIDS services in Zambia through the middle of 2008.

\footnotetext{
${ }^{10}$ To maintain comparability across survey rounds, we apply this demographic group calculation to each survey round using survey-round specific data.
} 


\subsection{Descriptive statistics}

Table 1 reports descriptive statistics by DHS survey round, likely HIV status, and location relative to a health facility that distributed ART. Six key facts emerge from this table. The first three are apparent when comparing the full sample in 2001 (Column 1) to the full sample in 2007 (Column 6). First, although ART was virtually unavailable to the general public in Zambia in 2001, ART availability was relatively widespread by 2007 with $43 \%$ of the 2007 sample within $10 \mathrm{~km}$ of an ART clinic by 2007. Second, although adult female weight increased during this period, adult female height remained virtually unchanged. Third, education levels and urbanization have increased consistent with rapid development and growth in Zambia between 2001 and 2007.

A fourth fact comes from the comparison of high versus low HIV likelihood women (i.e. Columns 2 and 3 in 2001 and Columns 7 and 8 in 2007). High HIV likelihood women are taller, heavier, more educated, more urban, and more likely to have interacted with the health system as compared to low HIV likelihood women, consistent with existing evidence on the HIV-education gradient (Fortson 2008) and that HIV prevalence is higher among women in the middle of the age distribution who possess greater physical stature than younger or older women. Fifth, comparing Columns 4 and 5 in 2001 and Columns 9 and 10 in 2007 indicates that women who lived closer to locations where ART was introduced were also more likely to have these characteristics, consistent with ART being introduced disproportionately in high HIV prevalence locations. Sixth, higher likelihood of being HIV positive and proximity to local ART introduction were associated with greater weight gains between 2001 and 2007, whereas these characteristics were not associated with substantial differences in changes in height.

To help illustrate variation in our data in the timing of local ART introduction relative to respondent interview date, Figure 1 plots a histogram of this variable. While the distribution is not uniform, for the majority of the twelve-month event windows, each one contains at least 
five percent of the DHS respondents. Therefore, sufficient variation exists to investigate the pretreatment parallel trends assumption underlying our triple-difference approach, an assumption that we examine in more detail in Section 5.4. Further, the distribution to the right of 0 suggests that for many respondents ART was locally available long enough to generate epidemiological effects.

\section{Results}

\subsection{Effect of local ART on ART cascade}

Before turning to the analysis of respondent health, we examine the effects of local ART introduction on the "ART cascade," or the series of behavioral steps required to receive ART. The DHS data do not contain data on whether an individual was receiving ART at the time of the survey. Instead, Table 2 shows the estimated effect of local ART on two steps required to receive ART. First, the DHS asks whether the respondent visited a health clinic for themselves or their child in the 12 months preceding the survey. Column 1 contains the triple difference coefficient estimate from Equation (1) with an indicator variable for whether the respondent visited a clinic in the last 12 months as the dependent variable. As indicated by the coefficient estimate (and associated standard error) on the triple interaction term, we do not find statistically significant evidence of an effect of local ART availability on whether the respondent visited a health clinic. The health clinic visit result should be interpreted with caution for at least two reasons. First, as shown in Table 1, there was a 21 percentage point decline between 2001 and 2007 in the proportion of female respondents visiting a health clinic, likely indicating an overall increase in maternal and/or child health that could mask any direct change in visit behavior due to ART receipt. Second, a routine visit to a health clinic for ART medication may not be considered a traditional clinic visit. Column 2 contains an analogous specification with an indicator variable equal to one if the respondent reported having 
ever been tested for HIV. The point estimate on the triple interaction term suggests that local ART introduction increased the likelihood of the respondent having ever been tested for HIV by approximately 7 percentage points (statistically significant at the $5 \%$ level).

\subsection{Effect of local ART on adult female anthropometrics}

Prior to the estimation of Equation (1) with anthropometrics as dependent variables, we present prima facie evidence of effect. Table 3 presents the average weight and average height within the component cells of the triple difference comparison, effectively estimating Equation (1) without covariates. The sample is divided by local ART availability, HIV status, and survey round, the three sources of variation in the triple difference.

As explained in Section 4, respondents with an above median likelihood of being HIV positive based on their demographic group (i.e. defined as the interaction of survey round, gender, five year age group, urban/rural status, and province of residence) are considered "high likelihood HIV+" in the table. In Table 3, Column 1 contains the sample means from 2001 (prior to the availability of ART) and Column 2 contains the analogous means from 2007 (after some locations had ART locally available). ${ }^{11}$ Column 3 contains the differences between these two means, a single difference. Column 4 contains the double difference between the single differences in the previous two rows of Column 3. Column 5 displays the triple difference estimate, effectively $\beta$ from Equation (1) without controls. The triple difference estimate for weight in Panel A suggests local ART availability increased the weight of HIV positive women by approximately $1.2 \mathrm{~kg}$ or $2.3 \%$ of average female weight in 2001. The triple difference estimate for height suggests local ART

\footnotetext{
${ }^{11}$ Although the sample means in Column 1 indicate that individuals residing near locations where ART was subsequently introduced were slightly heavier than individuals residing in other locations, our triple-difference strategy addresses this heterogeneity. In particular, our triple-difference strategy identifies the causal effect of local ART introduction by further comparing high and low HIV likelihood individuals, addressing concerns about systematic differences in health by proximity to ART. In addition, as we demonstrate in Section 5.4, our semi-parametric tripledifference figure (i.e. Figure 2) reveals no differential pre-treatment trend in our triple-difference estimates.
} 
availability increased height by $0.33 \mathrm{~cm}$, or approximately a 0.2 percent change relative to 2001 .

This substantial increase in weight without a corresponding change in height is consistent with the physiological effects of receiving ART.

Table 4 presents regression estimates of our primary coefficient of interest, the triple difference parameter in Equation (1). ${ }^{12}$ Column 1 presents results with weight as the dependent variable and Column 2 presents the analogous results with height as the dependent variable. The point estimate on the triple interaction in Column 1 suggests that local ART introduction resulted in a weight gain of approximately $1.6 \mathrm{~kg}$ for women with above median HIV likelihood (statistically significant at the $5 \%$ level), or an increase of around $2.5 \%$ relative to mean weight in 2001 . In contrast, Column 2 shows that local ART availability appears to be associated with a statistically insignificant and small reduction in height of about $0.008 \mathrm{~cm}$, or less than $0.1 \%$ of mean height in $2001 .^{13}$ These relationships are what one would expect given the timing of ART availability and our focus on adults. Adults would have already reached their full stature prior to treatment, but improvements in health could translate into increased weight.

Columns 3 and 4 present results with body mass index (BMI) and BMI z-score, respectively, as the dependent variables. The results confirm that local ART introduction was associated with an increase in weight-for-height and not just weight. They also place the effect size in context: local ART introduction was associated with an approximately 0.17 standard deviation increase in the body mass of high HIV likelihood women.

In addition to our wealth of controls, the strong finding for weight without a corresponding change in height bolsters our claim that ART availability has caused this change. First, generally

\footnotetext{
${ }^{12}$ Even though lower level double and single difference terms are included in all regressions, the inclusion of a host of temporal and spatial controls (including their interactions) complicates their interpretation. Therefore, in order to avoid confusion, we report only the triple difference parameter in our main tables. In the Appendix, we present results that display the lower level triple-difference terms (e.g., the Year $2007_{t}$ times $H I V_{i j t}$ ). We discuss these results in the Appendix.

${ }^{13}$ The point values in Table 4 differ from the simple triple-difference calculations in Table 3 because the regression used for Table 4 includes the covariates in Equation (1).
} 
improving health or nutrition over time would likely appear in both height and weight. Second, differential migration by larger HIV positive individuals, while unlikely, does not appear to be driving the weight results. We provide additional evidence on migration in Section 5.5. Third, given the positive correlation between HIV infection and education found in Fortson (2008), one could be concerned that ART has changed the sample selection, keeping people with a higher health endowment alive. The lack of estimated change in height makes this unlikely. Therefore, local ART at scale appears to have increased the health of the targeted.

Our coefficient of interest must be scaled in order to compare it to other studies. To place our estimates in context, studies in various developing countries found weight gains of 2.6 to $10.3 \mathrm{~kg}$ after six to twelve months of treatment, with almost all reporting at least a $5 \mathrm{~kg}$ increase within six months of treatment initiation (Koenig et al. 2004, Severe et al. 2005, Saghayam et al. 2008, Koethe et al. 2010, Thirumurthy and Graff Zivin 2012). Of particular interest to the current study, Médecins sans Frontiéres South Africa et al. (2003) found in a clinic-based study in a previously untreated area in South Africa that ART initiation led to weight gains averaging $10 \mathrm{~kg}$. Our data include some women whose disease had not progressed to the clinical stage. If $20 \%$ of HIV positive women in our sample were clinically eligible for ART and one-half of these women accessed and received ART, then local ART availability should directly affect the health of approximately $10 \%$ of the local adult HIV positive female population. ${ }^{14}$ Therefore, the expected effect of local ART due to treatment alone, averaged across all HIV positive adult women, those who were and were not eligible for treatment, is a roughly $1 \mathrm{~kg}$ increase in body mass, approximately two-thirds of our estimate. Recall that our estimate includes both the direct and indirect effects of treatment. While not all HIV positive women were clinically eligible for treatment, other studies have found that

\footnotetext{
${ }^{14}$ During the period examined in the current analysis, the World Health Organization (WHO) recommended initiating ART for HIV patients in WHO clinical stages "III" or "IV" and for HIV patients with CD4 counts between 200 and 350 cells $/ \mathrm{mm}$ (WHO 2006b). Clinical practice appears to have largely followed these guidelines (Stringer et al. 2006).
} 
the availability of ART increased household maize production by increasing mental health even for those not under treatment, potentially accounting for the additional weight gain we observe (Baranov et al. 2015). Although our estimated effects of local ART introduction are relatively large, they are consistent with a highly successful ART campaign.

\subsection{Spatial heterogeneity}

Initiating and adhering to ART requires a patient to make regular trips to a clinic for health examinations and to receive medications. Our estimates thus far assumed that individuals more than $10 \mathrm{~km}$ from a location where ART was introduced would have been unlikely to initiate and adhere to ART. Table 5 examines spatial heterogeneity in the estimated effect of local ART on weight. We relax the restriction that the local introduction of ART affected all individuals more than $10 \mathrm{~km}$ from an ART health facility uniformly. To do this, we include an additional measure of distance in Equation (1) that takes a value of 1 if a household resided within $20 \mathrm{~km}$ of a facility with ART availability. We also include the appropriate double and triple interactions using this new distance measure. This distance measure is not mutually exclusive with our existing measure: a household that resides within $10 \mathrm{~km}$ of ART also resides within $20 \mathrm{~km}$ of ART. Therefore, the estimated effect for individuals within $10 \mathrm{~km}$ is the sum of the two triple interaction coefficients. For those respondents residing between $10 \mathrm{~km}$ and $20 \mathrm{~km}$, the estimated effect is simply the coefficient estimate on the new triple interaction term (i.e. "ART ever within $20 \mathrm{~km} \mathrm{X} \mathrm{Year} 2007$ X HIV+"). As expected, the results suggest that the statistically measurable effect of local ART introduction on female health was limited to those within $10 \mathrm{~km}$ as can be seen by the statistically insignificant coefficient on the $20 \mathrm{~km}$ triple interaction term. 


\subsection{Parallel trends assumption and timing}

One concern with our identification strategy is the presence of differential pre-ART trends by HIV status and clinic distance. While we have no reason to believe such trends existed, any such trends would be evident in a semi-parametric triple difference specification in which we allow a more flexible timing of any effect of ART availability. ${ }^{15}$ To do this, first we define 9 mutually exclusive and completely exhaustive event windows based on when ART was locally available relative to DHS respondent interview date: 6 windows prior to the introduction and 3 windows after introduction.

16 Then we estimate the following semi-parametric triple difference regression specification:

$$
\begin{aligned}
\text { health }_{i j t}= & \sum_{k=1}^{9} \alpha_{k} 1\left(\tau_{t}=k\right) \times A R T_{j}+\sum_{k=1}^{9} \beta_{k} 1\left(\tau_{t}=k\right) \times A R T_{j} \times H I V_{i j t} \\
& +\gamma_{1} Y \text { Year } 2007_{t}+\gamma_{2} H I V_{i j t}+\gamma_{3} Y \text { ear } 2007_{t} \times H I V_{i j t} \\
& +Z_{i j t}^{\prime} \Gamma+\eta_{\text {district }}+\delta_{t}+\varepsilon_{i j t}
\end{aligned}
$$

where $\tau_{t}$ denotes the nine event windows and other notation is the same as in Equation (1). In the absence of differential trending, the estimates for $\beta_{k}$ for the six windows prior to introduction ( $k=1$ to 6 ) should show no pattern while the estimates for $\beta_{k}$ for the three windows after local ART introduction ( $k=7$ to 9$)$ should demonstrate treatment effects.

The ordinary least squares regression estimates of the semi-parametric triple difference parameters (i.e. $\beta_{k}$ in Equation (2)) from a regression with respondent weight as the dependent variable

\footnotetext{
${ }^{15}$ We are able to test for differential pre-treatment trends despite only having two rounds of survey data (i.e. the 2001 DHS and 2007 DHS). In particular, we exploit variation in the timing of local ART introduction. For individuals in a given survey round, substantial variation exists in the amount of time between the survey and when ART was locally introduced.

${ }^{16}$ The 6 windows prior to introduction are more than 60 months, 59 to 48 months, 47 to 36 months, 35 to 24 months, 23 to 12 months, and 11 to 0 months prior to introduction. The three windows after introduction are 1 to 11 months, 12 to 23 months, and more than 24 months. Because of the timing of our data collection we cannot extend these windows further.
} 
are plotted in Figure 2 and support a causal interpretation of the baseline anthropometric results. In the figure, negative numbers on the horizontal axis indicate windows prior to local ART introduction. As all coefficient estimates in this region of the figure are close to 0 and statistically insignificant, we do not find a differential pre-local ART introduction trend by HIV status. In addition, the timing of the increase in adult female weight is closely associated with the timing of local ART introduction, with the expected lag.

We also estimate Equation (2) using height as the depending variable, yielding another dynamic placebo test. Figure 3 plots the semi-parametric triple difference parameters from this regression. Again, these estimates fail to suggest any evidence of a differential pre-introduction trend and fail to suggest a differential change in sample composition coincident with the timing of local ART introduction.

\subsection{Robustness checks}

While all evidence indicates a causal interpretation of our findings, Table 6 presents estimates of the parameter of interest in versions of Equation (1) that include additional covariates or an alternative measure of HIV status. One concern could be that we are measuring other HIV/AIDS services, not ART, but recall that our primary specification of interest included controls for both local PMTCT and VCT availability, therefore our results are the effect of ART, not the two other HIV services. The first five columns of Table 6 contain additional control variables in order to demonstrate that other health or demographic changes are not driving our results.

In Columns 1 and 2 we control for two other public health improvements. Column 1 includes a control for household access to piped water and Column 2 controls for household bed net ownership. In both cases the results are quite similar to those that appear in Column 1 of Table 4. Column 3 controls for marital status of the respondent, again with only small changes to the coefficient 
of interest. Other potential concerns are that our effect is picking up a differential likelihood in pregnancy or in-migration of heavier individuals. Column 4 controls for whether the respondent was pregnant at the time of the survey, and Column 5 controls for whether the individual had resided in her household for less than one year. Again, these columns confirm the previous results. We do not include these controls in our primary specification as ART could also affect these outcomes. We include them to demonstrate that their exclusions are not driving the results in Table 4.

Finally, Column 6 uses a continuous measure of HIV likelihood, the age-group, gender, urban/rural, province cell level average, instead of the binary measure in the baseline specifications. In this column the point estimate on the triple interaction term is larger than in our baseline estimates. Because of the change in our HIV measure, this value is not immediately comparable to the other columns. The point estimate on the triple interaction indicates a weight gain of roughly 5.4 $\mathrm{kg}$ for someone with a likely HIV status equal to 1 . However, no observations have this value and the 90th percentile of likely HIV status is 0.333 . To scale this coefficient consider the estimated effect for a respondent in the 90th percentile of likely HIV status versus a respondent in the 10th percentile of likely HIV status (i.e. 0.333 versus 0.034 ). This comparison suggests an expected weight gain of approximately $1.60 \mathrm{~kg}$, a large, but not unreasonable change in weight, and one consistent with the other results in the table. Throughout, the estimates suggest that local ART introduction increased adult female weight.

\section{Conclusion}

A fundamental debate in development and growth is whether foreign aid can be effective at promoting sustained improvements in quality of life (e.g., Boone 1996, Burnside and Dollar 2000, Collier and Dollar 2002, Easterly 2003, Collier and Dollar 2004, Easterly et al. 2004, Easterly 2007, Easterly 2009). We raise a related and more narrowly defined question: can targeted aid for drug 
provision improve the health of the targeted at scale? We examine this topic in the context of arguably the single largest foreign aid health program in the history of the world, the United States President's Emergency Plan for AIDS Relief (PEPFAR), a program directed toward addressing the leading cause of death in the poorest region of the world. Our findings suggest that local ART introduction in Zambia, a PEPFAR focus country, substantially increased the weight of high HIV likelihood adult females, consistent with a reduction in HIV/AIDS morbidity due to local drug provision. These results suggest that despite limited local health sector capacity a very large foreign health aid program focused on drug provision improved the health of the targeted. 


\section{References}

Almond, Douglas, Hilary Hoynes, and Diane Whitmore Schanzenbach. 2011. Inside the war on poverty: The impact of the food stamp program on birth outcomes. Review of Economics and Statistics, 93(2): 387-403.

Baranov, Victoria, Daniel Bennett, and Hans-Peter Kohler. 2015. The indirect impact of antiretroviral therapy: Mortality risk, mental health, and HIV-negative labor supply. Journal of Health Economics, forthcoming.

Barre-Sinoussi, Francoise. 2011. Toward an H.I.V. cure. New York Times, June 3, 2011.

Basinga, Paulin, Paul Gertler, Agnes Binagwaho, Agnes Soucat, Jennifer Sturdy, Christel Vermeersch. 2011. Effect on maternal and child health services in Rwanda of payment to primary health-care providers for performance: an impact evaluation. The Lancet, 377(9775): 1421-1428.

Bate, Roger, Ginger Zhe Jin, Aparna Mathur. 2011. Does price reveal poor-quality drugs? Evidence from 17 countries. Journal of Health Economics, 30: 1150-1163.

Bendavid, Eran, Charles Holmes, Jay Bhattacharya, and Grant Miller. 2012. HIV development assistance and adult mortality in Africa. Journal of the American Medical Association, 307(19): 2060-2067.

Björkman-Nyqvist, Martina, Jakob Svensson, David Yanagizawa-Drott. 2012. Can good products drive out bad? Evidence from local markets for (fake?) antimalarial medicine in Uganda. Centre for Economic Policy Research Working Paper No. 9114.

Boone, Peter. 1996. Politics and the effectiveness of foreign aid. European Economic Review, 40: 289-329.

Bor, J, AJ Herbst, ML Newell, T. Barnighausen. 2013. Increases in adult life expectancy in rural South Africa: valuing the scale-up of HIV treatment. Science. 339: 961-965.

Burnside, Craig, and David Dollar. 2000. Aid, policies, and growth. American Economic Review, 90(4): 847-868.

Cameron, A. Colin, Jonah Gelbach, and Douglas Miller. 2008. Bootstrap-based improvements for inference with clustered errors. Review of Economics and Statistics, 90(3): 414-427.

Cantrell RA, Sinkala M, Megazinni K, et al. 2008. A pilot study of food supplementation to improve adherence to antiretroviral therapy among food-insecure adults in Lusaka, Zambia. Journal of Acquired Immune Deficiency Syndrome, 49: 190?195.

Card, David, Carlos Dobkin, and Nicole Maestas. 2008. The impact of nearly universal health coverage on health care utilization: Evidence from Medicare. American Economic Review, 98(5): $2242-2258$.

Card, David, Carlos Dobkin, and Nicole Maestas. 2009. Does Medicare save lives? Quarterly Journal of Economics, 124(2): 597-636.

Central Statistical Office, Ministry of Health, Tropical Diseases Research Centre, University of Zam- 
bia, and Macro International Inc. 2009. Zambia Demographic and Health Survey 2007. Calverton, Maryland, USA: CSO and Macro International Inc.

Collier, Paul and David Dollar. 2002. Aid allocation and poverty reduction. European Economic Review, 46(8): 1475-1500.

Collier, Paul and David Dollar. 2004. Development effectiveness: What have we learnt? Economic Journal, 114(496): F244-F271.

de Cock, Kevin, Wafaa El-Sadr, and Tedros Ghebreyesus. 2011. Game changers: Why did the scaleup of HIV treatment work despite weak health systems? Journal of Acquired Immune Deficiency Syndromes, 57(suppl 2): s61-s63.

de Walque, Damien, Haroun Kazianga, and Mead Over. 2012. Antiretroviral therapy, perceived efficacy, and risky sexual behaviors: Evidence from Mozambique. Economic Development and Cultural Change, 61(1): 97-126.

Easterly, William. 2003. Can foreign aid buy growth? Journal of Economic Perspectives, 17(3): 23-48.

Easterly, William. 2007. Was development assistance a mistake? American Economic Review Papers and Proceedings, 97(2): 328-332.

Easterly, William. 2009. Can the West save Africa? Journal of Economic Literature, 47(2):373-447.

Easterly, William, Ross Levine, and David Roodman. 2004. New data, new doubts: A Comment on Burnside and Dollars "Aid, Policies, and Growth". American Economic Review, 94(3).

Fan, Victoria, Rachel Silverman, Denizhan Duran, and Amanda Glassman. 2013a. The financial flows of PEPFAR: A profile. Center for Global Development Policy Paper 027, July 2013.

Fan, Victoria, Denizhan Duran, Rachel Silverman, and Amanda Glassman. 2013b. HIV/AIDS intervention packages in five countries: A review of budget data. Center for Global Development Policy Paper 033, October 2013.

Fauci, Anthony and Hilary Marsten. 2013. Achieving an AIDS-free world: Science and implementation. The Lancet, 382(9903): 1461-62.

Finkelstein, Amy. 2007. The aggregate effects of health insurance: Evidence from the introduction of Medicare. Quarterly Journal of Economics, 122 (1): 1-37.

Finkelstein, Amy, Sarah Taubman, Bill Wright, Mira Bernstein, Jonathan Gruber, Joseph P. Newhouse, Heidi Allen, Katherine Baicker and Oregon Health Study Group. 2012. The Oregon health insurance experiment: Evidence from the first year. Quarterly Journal of Economics, 127(3): 10571106.

Fortson, Jane. 2008. The gradient in sub-Saharan Africa: Socioeconomic status and HIV/AIDS. Demography, 45(2): 303-322.

Friedman, Willa. 2013. Antiretroviral drug access and behavior change. University of California, Berkeley working paper.

Global Fund to Fight AIDS, Tuberculosis, and Malaria. 2012. The Global Fund to Fight AIDS, 
Tuberculosis and Malaria, Grants Portfolio.

Goldstein, Markus, Joshua Graff Zivin, James Habyarimana, Cristian Pop-Eleches, Harsha Thirumurthy. 2012. The effect of health worker absence and health clinic protocol on health outcomes: The case of mother-to-child transmission of HIV in Kenya. American Economic Journal: Applied Economics, 5(2): 58-85.

Government Accountability Office (GAO, United States). 2010. Trends in U.S. Spending for Global HIV/AIDS and Other Health Assistance in Fiscal Years 2001-2008. GAO-11-64 Global Health.

Graff Zivin Joshua, Markus Goldstein, Thirumurthy Harsha. 2009. AIDS treatment and intrahousehold resource allocations: Childrens nutrition and schooling in Kenya. Journal of Public Economics, 93: 1008-15.

Gruber, Jonathan, Nathaniel Hendren, and Robert Townsend. 2014. The great equalizer: Health care access and infant mortality in Thailand. American Economic Journal: Applied Economics, 6(1): 91-107.

Hoynes, Hilary and Diane Whitmore Schanzenbach. 2009. Consumption responses to in-kind transfers: Evidence from the introduction of the food stamp program. American Economic Journal: Applied Economics Vol. 1, No. 4: 109-139.

Hoynes, Hilary, Marianne Page, and Ann Stevens. 2011. Can targeted transfers improve birth outcomes? Evidence from the introduction of the WIC program. Journal of Public Economics, 95(7-8): $813 ? 827$.

Jayachandran, Seema, Adriana Lleras-Muney, and Kimberly V. Smith. 2010. Modern medicine and the twentieth century decline in mortality: Evidence on the impact of sulfa drugs. American Economic Journal: Applied Economics, 2(2): 118-46.

Kober, Katharina and Wim Van Damme. 2004. Scaling up access to antiretroviral treatment in southern Africa: who will do the job? Lancet, 364: 10307.

Koenig, Serena, Fernet Le Andre, and Paul E. Farmer. 2004. Scaling-up HIV treatment programmes in resource limited settings: the rural Haiti experience. AIDS, 18(suppl 3):S21?S25

Koethe, Anna Lukusa, Mark J. Giganti, Benjamin H. Chi, Christopher K. Nyirenda, Mohammed I. Limbada, Yolan Banda, and Jeffrey S. A. Stringer. 2010. Association between weight gain and clinical outcomes among malnourished adults initiating antiretroviral therapy in Lusaka, Zambia. Journal of Acquired Immune Deficiency Syndrome, 53(4): 507-513.

Lucas, Adrienne and Nicholas Wilson. 2013. Adult antiretroviral therapy and child health: Evidence from scale-up in Zambia. American Economic Review Papers and Proceedings, 103(3).

Lucas, Adrienne and Nicholas Wilson. 2015. Adult health interventions at scale and children's schooling: Evidence from antiretroviral therapy in Zambia. University of Delaware working paper.

McLaren, Zoë. 2010. The effect of access to AIDS treatment on employment outcomes in South Africa. University of Michigan working paper.

Médecins sans Frontiéres South Africa, the Department of Public Health at the University of Cape Town, and the Provincial Administration of the Western Cape, South Africa. 2003. Antiretroviral therapy in primary health care: Experience of the Khayelitsha programme in South Africa. World 
Health Organization.

Miller, Grant, Diana Pinto, and Marcos Vera-Hernández. 2013. Risk protection, service use, and health outcomes under Colombia's health insurance program for the poor. American Economic Journal: Applied Economics, 5(4): 61-91.

Mills, Edward, Richard Lester, Kristian Thorlund, Maria Lorenzi, Katherine Muldoon, Steve Kanters, Sebastian Linnemayr, Robert Gross, Yvette Calderon, K Rivet Amico, Harsha Thirumurthy, Cynthia Pearson, Robert H Remien, Lawrence Mbuagbaw, Lehana Thabane, Michael H Chung, Ira B Wilson, Albert Liu, Olalekan A Uthman, Jane Simoni, David Bangsberg, Sanni Yaya, Till B?rnighausen, Nathan Ford, Jean B Nachega. 2014. Interventions to promote adherence to antiretroviral therapy in Africa: a network meta-analysis. The Lancet HIV, 1(3): e104-e111.

Moss, Kellie. 2008. International HIV/AIDS, Tuberculosis, and Malaria: Key Changes to U.S. Programs and Funding. CRS Report for Congress. August 25, 2008.

Oomman, Nandini, Michael Bernstein, Steven Rosenzweig. 2007. Following the Funding for HIV/AIDS: A Comparative Analysis of the Funding Practices of PEPFAR, the Global Fund and World Bank MAP in Mozambique, Uganda and Zambia. Center for Global Development working paper.

Palella FJ, Delaney KM, Moorman AC, et al. 1998. Declining morbidity and mortality among patients with advanced human immunodeficiency virus infection. New England Journal of Medicine, 338: $853-860$.

PEPFAR. 2013. The President's Emergency Plan for AIDS Relief: Ambassdor's Welcome. http://zambia.usembassy.gov/pepfar.html

Resch, Stephen, Michelle Lee, Gilbert Kombe, Elijah Sinyinza. 2008. Sustainability Analysis of HIV/AIDS Services in Zambia. Bethesda, MD: Health Systems 20/20 project, Abt Associates Inc.

Schneider, Kammerle, and Laurie Garrett. 2009. The evolution and future of donor assistance for HIV/AIDS. Council on Foreign Relations Working Paper.

Severe, Patrice, Paul Leger, Macarthur Charles, Francine Noel, Gerry Bonhomme, Gyrlande Bois, Erik George, Stefan Kenel-Pierre, Peter F. Wright, Roy Gulick, Warren D. Johnson, Jr, Jean William Pape, and Daniel W. Fitzgerald. 2005. Antiretroviral therapy in a thousand patients with AIDS in Haiti. New England Journal of Medicine, 353(22): 2325-2334.

Stringer, J., Zulu, I., Levy, J., Stringer, E., Mwango, A., Chi, B., Mtonga, V., Reid, S., Cantrell, R., Bulterys, M., Saag, M., Marlink, R., Mwinga, A., Ellerbrock, T., Sinkala, M. 2006. Rapid scale-up of antiretroviral therapy at primary care sites in Zambia: Feasibility and early outcomes. Journal of the American Medical Association, 296(7), 782-793.

Saghayam, Suneeta, N. Kumarasamy, Anitha J. Cecelia, Suniti Solomon, Kenneth Mayer, and Christine Wanke. 2007. Weight and body shape changes in a treatment naive population after 6 months of nevirapine based generic highly active antiretroviral therapy in South India. Clinical Infectious Disease, 44: 295-300.

Tarnoff, Curt and Marian Leonardo Lawson. 2011. Foreign Aid: An Introduction to U.S. Programs and Policy. Congressional Research Service, 7-5700, R40213. 
Thirumurthy, Harsha, Joshua Graff Zivin, and Markus Goldstein. 2008. The economic impact of AIDS treatment on labor supply in Western Kenya. Journal of Human Resources, 43: 511-552.

Thirumurthy, Harsha and Joshua Graff Zivin. 2012. Health and labor supply in the context of HIV/AIDS: The long-run economic impacts of antiretroviral therapy. Economic Development and Cultural Change, 61(1): 73-96.

UNAIDS. 2006. Report on the Global AIDS Epidemic.

UNAIDS. 2010. Global Report: UNAIDS Report on the Global AIDS Epidemic.

United States Department of Health and Human Services. 2011. HIV study named 2011 Breakthrough of the Year by Science: NIH-funded treatment-as-prevention study heralded as a major advance. NIH News, National Institutes of Health, December 22, 2011.

WHO. 2006a. Working Together for Health. World Health Report 2006. World Health Organization.

WHO. 2006b. Antiretroviral Therapy for HIV infection in Adults and Adolescents: Recommendations for a Public Health Approach. The World Health Organization.

WHO. 2011. Causes of Death Summary Tables. Health Statistics and Informatics Department, World Health Organization. Geneva, Switzerland.

Wilson, Nicholas. 2015. Can disease specific funding harm health? Child mortality in the shadow of HIV/AIDS service expansion. Demography, 52(5):1671-1700.

World Bank. 2013. World Development Indicators 2012. data.worldbank.org/data-catalog/worlddevelopment-indicators 
Table 1: Descriptive Statistics for Adult Female Respondents in the 2001 and 2007 Demographic Health Surveys

\begin{tabular}{|c|c|c|c|c|c|c|c|c|c|c|}
\hline \multirow{2}{*}{$\begin{array}{l}\text { Survey round: } \\
\text { Sub-sample: }\end{array}$} & \multicolumn{5}{|c|}{2001} & \multicolumn{5}{|c|}{2007} \\
\hline & $\begin{array}{c}\begin{array}{c}\text { Full } \\
\text { sample }\end{array} \\
(1)\end{array}$ & $\begin{array}{c}\text { High } \\
\text { likehihood } \\
\text { HIV+ } \\
(2)\end{array}$ & $\begin{array}{c}\text { Low } \\
\text { likehihood } \\
\text { HIV+ }\end{array}$ & $\begin{array}{c}\text { ART } \\
\text { ever } \\
\text { within } \\
10 \mathrm{~km} \\
(4) \\
\end{array}$ & $\begin{array}{c}\text { ART } \\
\text { further } \\
\text { than } 10 \mathrm{~km} \\
(5)\end{array}$ & $\begin{array}{c}\begin{array}{c}\text { Full } \\
\text { sample }\end{array} \\
(6)\end{array}$ & $\begin{array}{c}\text { High } \\
\text { likehihood } \\
\text { HIV+ } \\
(7)\end{array}$ & $\begin{array}{l}\text { Low } \\
\text { likehihood } \\
\text { HIV+ } \\
(8)\end{array}$ & $\begin{array}{c}\text { ART } \\
\text { ever } \\
\text { within } \\
10 \mathrm{~km} \\
(9) \\
\end{array}$ & $\begin{array}{c}\begin{array}{c}\text { ART } \\
\text { further } \\
\text { than } 10 \mathrm{~km}\end{array} \\
(10) \\
\end{array}$ \\
\hline ART within $10 \mathrm{~km}$ & $\begin{array}{c}0.00 \\
(0.00)\end{array}$ & $\begin{array}{c}0.00 \\
(0.00)\end{array}$ & $\begin{array}{c}0.00 \\
(0.00)\end{array}$ & $\begin{array}{c}0.00 \\
(0.00)\end{array}$ & $\begin{array}{c}0.00 \\
(0.00)\end{array}$ & $\begin{array}{c}0.43 \\
(0.50)\end{array}$ & $\begin{array}{c}0.57 \\
(0.50)\end{array}$ & $\begin{array}{c}0.29 \\
(0.45)\end{array}$ & $\begin{array}{c}1.00 \\
(0.00)\end{array}$ & $\begin{array}{c}0.00 \\
(0.00)\end{array}$ \\
\hline Weight, kilograms & $\begin{array}{l}53.20 \\
(9.47)\end{array}$ & $\begin{array}{c}55.20 \\
(10.10)\end{array}$ & $\begin{array}{l}51.40 \\
(8.48)\end{array}$ & $\begin{array}{c}55.40 \\
(10.50)\end{array}$ & $\begin{array}{l}51.60 \\
(8.24)\end{array}$ & $\begin{array}{c}56.20 \\
(11.00)\end{array}$ & $\begin{array}{c}59.00 \\
(12.00)\end{array}$ & $\begin{array}{l}53.20 \\
(8.96)\end{array}$ & $\begin{array}{c}58.30 \\
(12.10)\end{array}$ & $\begin{array}{l}53.90 \\
(9.19)\end{array}$ \\
\hline Height, centimeters & $\begin{array}{c}157.50 \\
(6.38)\end{array}$ & $\begin{array}{l}158.50 \\
(6.24)\end{array}$ & $\begin{array}{l}156.50 \\
(6.38)\end{array}$ & $\begin{array}{c}158.30 \\
(6.27)\end{array}$ & $\begin{array}{c}156.90 \\
(6.40)\end{array}$ & $\begin{array}{c}157.60 \\
(6.82)\end{array}$ & $\begin{array}{l}158.70 \\
(6.62)\end{array}$ & $\begin{array}{c}156.40 \\
(6.83)\end{array}$ & $\begin{array}{c}158.40 \\
(6.77)\end{array}$ & $\begin{array}{l}156.80 \\
(6.79)\end{array}$ \\
\hline BMI & $\begin{array}{l}21.40 \\
(3.32)\end{array}$ & $\begin{array}{l}21.90 \\
(3.63)\end{array}$ & $\begin{array}{l}20.90 \\
(2.90)\end{array}$ & $\begin{array}{l}22.10 \\
(3.73)\end{array}$ & $\begin{array}{l}20.90 \\
(2.87)\end{array}$ & $\begin{array}{l}22.60 \\
(3.98)\end{array}$ & $\begin{array}{l}23.40 \\
(4.41)\end{array}$ & $\begin{array}{l}21.70 \\
(3.25)\end{array}$ & $\begin{array}{l}23.20 \\
(4.36)\end{array}$ & $\begin{array}{l}21.90 \\
(3.40)\end{array}$ \\
\hline BMI z-score & $\begin{array}{c}-0.16 \\
(0.89)\end{array}$ & $\begin{array}{l}-0.02 \\
(0.98)\end{array}$ & $\begin{array}{l}-0.29 \\
(0.78)\end{array}$ & $\begin{array}{c}0.02 \\
(1.00)\end{array}$ & $\begin{array}{l}-0.29 \\
(0.77)\end{array}$ & $\begin{array}{c}0.15 \\
(1.07)\end{array}$ & $\begin{array}{c}0.37 \\
(1.19)\end{array}$ & $\begin{array}{l}-0.08 \\
(0.87)\end{array}$ & $\begin{array}{c}0.32 \\
(1.17)\end{array}$ & $\begin{array}{l}-0.03 \\
(0.91)\end{array}$ \\
\hline Primary school completion & $\begin{array}{c}0.45 \\
(0.50)\end{array}$ & $\begin{array}{c}0.51 \\
(0.50)\end{array}$ & $\begin{array}{c}0.39 \\
(0.49)\end{array}$ & $\begin{array}{c}0.62 \\
(0.48)\end{array}$ & $\begin{array}{c}0.31 \\
(0.46)\end{array}$ & $\begin{array}{c}0.55 \\
(0.50)\end{array}$ & $\begin{array}{c}0.63 \\
(0.48)\end{array}$ & $\begin{array}{c}0.47 \\
(0.50)\end{array}$ & $\begin{array}{c}0.68 \\
(0.47)\end{array}$ & $\begin{array}{c}0.42 \\
(0.49)\end{array}$ \\
\hline Secondary school completion & $\begin{array}{c}0.06 \\
(0.24)\end{array}$ & $\begin{array}{c}0.09 \\
(0.28)\end{array}$ & $\begin{array}{c}0.04 \\
(0.19)\end{array}$ & $\begin{array}{c}0.11 \\
(0.32)\end{array}$ & $\begin{array}{c}0.02 \\
(0.14)\end{array}$ & $\begin{array}{c}0.11 \\
(0.31)\end{array}$ & $\begin{array}{c}0.18 \\
(0.38)\end{array}$ & $\begin{array}{c}0.04 \\
(0.20)\end{array}$ & $\begin{array}{c}0.17 \\
(0.38)\end{array}$ & $\begin{array}{c}0.04 \\
(0.21)\end{array}$ \\
\hline Urban & $\begin{array}{c}0.31 \\
(0.46)\end{array}$ & $\begin{array}{c}0.39 \\
(0.49)\end{array}$ & $\begin{array}{c}0.23 \\
(0.42)\end{array}$ & $\begin{array}{c}0.62 \\
(0.49)\end{array}$ & $\begin{array}{c}0.07 \\
(0.25)\end{array}$ & $\begin{array}{c}0.45 \\
(0.50)\end{array}$ & $\begin{array}{c}0.65 \\
(0.48)\end{array}$ & $\begin{array}{c}0.23 \\
(0.42)\end{array}$ & $\begin{array}{c}0.74 \\
(0.44)\end{array}$ & $\begin{array}{c}0.13 \\
(0.34)\end{array}$ \\
\hline Visited clinic in past 12 months & $\begin{array}{c}0.66 \\
(0.47)\end{array}$ & $\begin{array}{c}0.73 \\
(0.44)\end{array}$ & $\begin{array}{c}0.59 \\
(0.49)\end{array}$ & $\begin{array}{c}0.69 \\
(0.50)\end{array}$ & $\begin{array}{c}0.64 \\
(0.48)\end{array}$ & $\begin{array}{c}0.45 \\
(0.50)\end{array}$ & $\begin{array}{c}0.51 \\
(0.50)\end{array}$ & $\begin{array}{c}0.38 \\
(0.49)\end{array}$ & $\begin{array}{c}0.48 \\
(0.50)\end{array}$ & $\begin{array}{c}0.42 \\
(0.49)\end{array}$ \\
\hline Ever took a HIV test & $\begin{array}{c}0.09 \\
(0.28)\end{array}$ & $\begin{array}{c}0.11 \\
(0.31)\end{array}$ & $\begin{array}{c}0.07 \\
(0.26)\end{array}$ & $\begin{array}{c}0.13 \\
(0.34)\end{array}$ & $\begin{array}{c}0.05 \\
(0.23)\end{array}$ & $\begin{array}{c}0.41 \\
(0.49)\end{array}$ & $\begin{array}{c}0.52 \\
(0.50)\end{array}$ & $\begin{array}{c}0.29 \\
(0.45)\end{array}$ & $\begin{array}{c}0.50 \\
(0.50)\end{array}$ & $\begin{array}{c}0.31 \\
(0.46)\end{array}$ \\
\hline Age & $\begin{array}{l}26.90 \\
(8.20)\end{array}$ & $\begin{array}{l}29.40 \\
(6.52)\end{array}$ & $\begin{array}{l}24.40 \\
(8.86)\end{array}$ & $\begin{array}{l}26.40 \\
(7.94)\end{array}$ & $\begin{array}{l}27.20 \\
(8.38)\end{array}$ & $\begin{array}{l}27.90 \\
(9.22)\end{array}$ & $\begin{array}{l}30.80 \\
(7.82)\end{array}$ & $\begin{array}{l}24.80 \\
(9.55)\end{array}$ & $\begin{array}{l}27.50 \\
(9.21)\end{array}$ & $\begin{array}{l}28.30 \\
(9.22)\end{array}$ \\
\hline Likely HIV positive & $\begin{array}{c}0.17 \\
(0.14)\end{array}$ & $\begin{array}{c}0.27 \\
(0.13)\end{array}$ & $\begin{array}{c}0.07 \\
(0.04)\end{array}$ & $\begin{array}{c}0.19 \\
(0.15)\end{array}$ & $\begin{array}{c}0.15 \\
(0.13)\end{array}$ & $\begin{array}{c}0.17 \\
(0.12)\end{array}$ & $\begin{array}{c}0.26 \\
(0.10)\end{array}$ & $\begin{array}{c}0.07 \\
(0.04)\end{array}$ & $\begin{array}{c}0.21 \\
(0.14)\end{array}$ & $\begin{array}{c}0.12 \\
(0.09)\end{array}$ \\
\hline Observations & 6,645 & 3,240 & 3,405 & 2,881 & 3,764 & 7,039 & 3,608 & 3,441 & 3,635 & 3,404 \\
\hline
\end{tabular}

Notes: Data come from the 2001 and 2007 Zambia Demographic Health Surveys. Entries are sample means. Standard deviations are in parentheses. ART

within $10 \mathrm{~km}$ is an indicator variable equal to one if a clinic located within $10 \mathrm{~km}$ of the respondent offered ART at least twelve months prior to the

respondent's survey date. 
Table 2: Effect of Local ART on ART Cascade

\begin{tabular}{lcc}
\hline \hline \multirow{2}{*}{ Dependent variable: } & $\begin{array}{c}\text { Visited } \\
\text { clinic }\end{array}$ & $\begin{array}{c}\text { Ever } \\
\text { tested }\end{array}$ \\
\cline { 2 - 3 } ART ever within 10km X Year 2007 X HIV + & $(1)$ & $(2)$ \\
Observations & 0.013 & $\begin{array}{c}0.073 * * \\
(0.033)\end{array}$ \\
\hline \hline
\end{tabular}

Notes: Data come from the 2001 and 2007 Zambia Demographic Health Surveys. All dependent variables are indicator variables. "ART ever within $10 \mathrm{~km}$ " is an indicator variable equal to one if a health clinic with 10 kilometers of the respondent offered ART at least twelve months prior to the 2007 DHS. HIV + is an indicator variable equal to one if respondent is in a demographic group with HIV prevalence above median. All specifications include the full set of controls, including lower level triple difference terms, indicated in Equation (1). Parameters estimated using ordinary least squares (OLS) regression. Standard errors are in parentheses and are clustered by Standard Enumeration Area (SEA).

*** Significant at the 1 percent level, ${ }^{* *}$ Significant at the 5 percent level, * Significant at the 10 percent level. 
Table 3: Adult Female Anthropometrics in Zambia by Proximity to ART, HIV Prevalence, and Survey Year

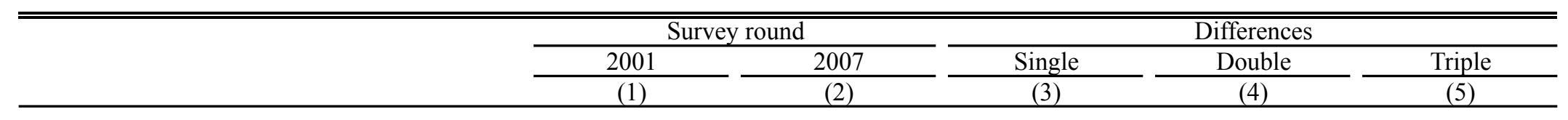

\section{Panel A: Weight, kilograms}

(1) ART ever within 10km, high likelihood HIV+

56.78

60.65

3.87

(2) ART ever within $10 \mathrm{~km}$, low likelihood HIV+

52.90

54.29

1.39

(3) Double difference

53.08

56.28

(4) ART further than $10 \mathrm{~km}$, high likelihood HIV+

50.69

52.61

3.20

(5) ART further than $10 \mathrm{~km}$, low likelihood HIV+

50.69

(6) Double difference

(7) Triple difference

\section{Panel B: Height, centimeters}

$\begin{array}{lccr}\text { (8) ART ever within 10km, high likelihood HIV+ } & 158.34 & 159.20 & 0.86 \\ \begin{array}{l}\text { (9) ART ever within 10km, low likelihood HIV+ } \\ \text { (10) Double difference }\end{array} & 157.08 & 157.14 & 0.06 \\ \text { (11) ART further than 10km, high likelihood HIV- } & 158.30 & 158.19 & -0.11 \\ \text { (12) ART further than 10km, low likelihood HIV+ } & 156.58 & 156.00 & -0.58\end{array}$

(13) Double difference

(14) Triple difference

0.33

Notes: Anthropometric data come from the 2001 and 2007 Zambia Demographic Health Surveys. Entries are sample means. "ART ever within 10km" and "ART further than 10km" refer to ART availability at least twelve months prior to the 2007 DHS. "High likelihood HIV+" and "low likelihood HIV+" refer to whether HIV prevalence in the respondent's demographic group is above or below the median HIV prevalence demographic group, respectively. 
Table 4: Effect of Local ART on Adult Female Weight and Height

\begin{tabular}{|c|c|c|c|c|}
\hline Dependent variable: & $\begin{array}{c}\text { Weight }(\mathrm{kg}) \\
(1)\end{array}$ & $\frac{\text { Height }(\mathrm{cm})}{(2)}$ & $\begin{array}{l}\text { BMI } \\
(3) \\
\end{array}$ & $\begin{array}{c}\text { BMI z-score } \\
(4)\end{array}$ \\
\hline ART ever within 10km X Year 2007 X HIV + & $\begin{array}{l}1.619 * * \\
(0.642)\end{array}$ & $\begin{array}{l}-0.008 \\
(0.451)\end{array}$ & $\begin{array}{c}0.624 * * \\
(0.252)\end{array}$ & $\begin{array}{c}0.168 * * \\
(0.068)\end{array}$ \\
\hline Observations & 13,684 & 13,668 & 13,662 & 13,662 \\
\hline $\begin{array}{l}\text { Notes: Data come from the } 2001 \text { and } 2007 \text { Zan } \\
\text { an indicator variable equal to one if a health cli } \\
\text { twelve months prior to the } 2007 \text { DHS. HIV } \\
\text { demographic group with HIV prevalence above } \\
\text { including lower level triple difference terms, in } \\
\text { least squares (OLS) regression. Standard errors } \\
\text { Area (SEA). }\end{array}$ & $\begin{array}{l}\text { ographic Hea } \\
10 \text { kilometers } \\
\text { cator variable } \\
\text { All specifica } \\
\text { n Equation (1) } \\
\text { arentheses and }\end{array}$ & $\begin{array}{l}\text { th Surveys. ". } \\
\text { of the respon } \\
\text { equal to one i } \\
\text { ions include t } \\
\text { Parameters } \\
\text { are clustered }\end{array}$ & $\begin{array}{l}\text { RT ever W } \\
\text { nt offered } \\
\text { espondent } \\
\text { full set o } \\
\text { timated us } \\
\text { y Standard }\end{array}$ & $\begin{array}{l}\text { hin } 10 \mathrm{~km} " \text { is } \\
\mathrm{RT} \text { at least } \\
\mathrm{s} \text { in a } \\
\text { controls, } \\
\text { g ordinary } \\
\text { Enumeration }\end{array}$ \\
\hline
\end{tabular}

*** Significant at the 1 percent level, ** Significant at the 5 percent level, * Significant at the 10 percent level. 
Table 5: Spatial Heterogeneity in Effect of Local ART on Adult Female Weight

\begin{tabular}{lc}
\hline \hline Dependent variable: & Weight $(\mathrm{kg})$ \\
\cline { 2 - 2 } ART ever within 10km X Year 2007 X HIV + & $(1)$ \\
& $1.883^{* *}$ \\
ART ever within 20km X Year 2007 X HIV + & $(0.843)$ \\
& -0.415 \\
Observations & $(0.765)$ \\
\hline \hline
\end{tabular}
Notes: Data come from the 2001 and 2007 Zambia Demographic Health Surveys. "ART ever within 10km" is an indicator variable equal to one if a health clinic with 10 kilometers of the respondent offered ART at least twelve months prior to the 2007 DHS. "ART ever within $20 \mathrm{~km}$ " is defined analogously using a 20 kilometer cutoff. $\mathrm{HIV}+$ is an indicator variable equal to one if respondent is in a demographic group with HIV prevalence above median. All specifications include the full set of controls, including lower level triple difference terms, indicated in Equation (1). Parameters estimated using ordinary least squares (OLS) regression. Standard errors are in parentheses and are clustered by Standard Enumeration Area (SEA).

*** Significant at the 1 percent level, ** Significant at the 5 percent level, * Significant at the 10 percent level. 
Table 6: Robustness Checks for Effect of Local ART on Adult Female Weight

\begin{tabular}{lcccccc}
\hline \hline Dependent variable: & \multicolumn{6}{c}{ Weight (kg) } \\
\cline { 2 - 6 } & $(1)$ & $(2)$ & $(3)$ & $(4)$ & $(5)$ & $(6)$ \\
\hline ART ever within 10km X Year 2007 X HIV + & $\begin{array}{c}1.560^{* *} \\
(0.645)\end{array}$ & $\begin{array}{c}1.603^{* *} \\
(0.643)\end{array}$ & $\begin{array}{c}1.609^{* *} \\
(0.634)\end{array}$ & $\begin{array}{l}1.577^{* *} \\
(0.636)\end{array}$ & $\begin{array}{c}1.617^{* *} \\
(0.642)\end{array}$ & $\begin{array}{c}5.441^{*} \\
(3.001)\end{array}$ \\
Additional controls for & piped water bed net & married & pregnant & migrant &
\end{tabular}

Alternative HIV measure

continuous

measure of

HIV

prevalence

\begin{tabular}{lllllll} 
Observations & 13,681 & 13,683 & 13,684 & 13,684 & 13,673 & 13,684 \\
\hline
\end{tabular}

Notes: Data come from the 2001 and 2007 Zambia Demographic Health Surveys. "ART ever within 10km" is an indicator variable equal to one if a health clinic with 10 kilometers of the respondent offered ART at least twelve months prior to the 2007 DHS. In Columns (1) - (5), HIV + is an indicator variable equal to one if respondent is in a demographic group with HIV prevalence above median. In Column (6), HIV+ is a continous measure of HIV prevalence in the respondent's demographic group. All specifications include the full set of controls, including lower level triple difference terms, indicated in Equation (1). Parameters estimated using ordinary least squares (OLS) regression. Standard errors are in parentheses and are clustered by Standard Enumeration Area (SEA). *** Significant at the 1 percent level, ** Significant at the 5 percent level, * Significant at the 10 percent level. 


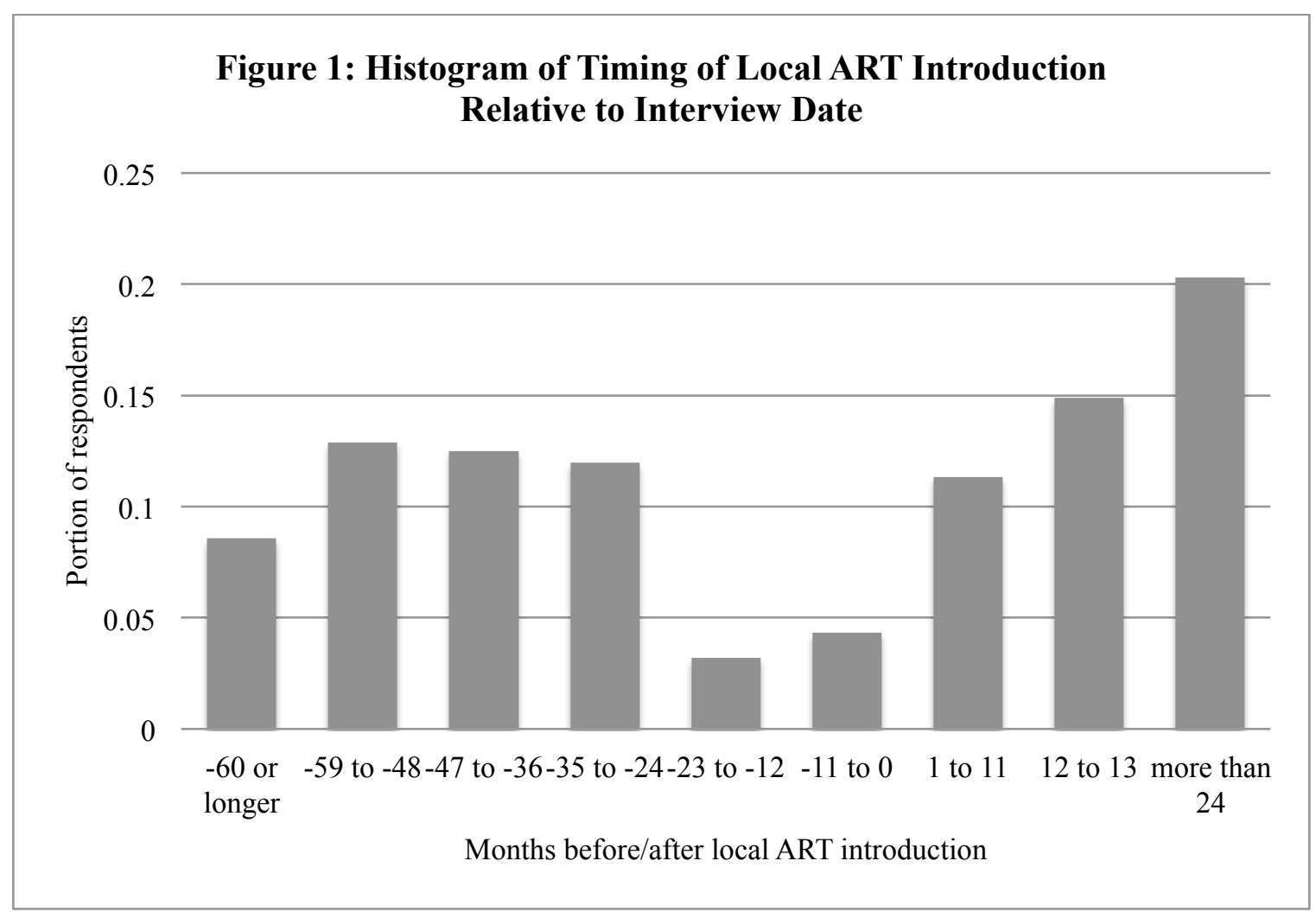

Notes: Each bar represents the percentage of respondents. The months are the number of months between the date of interview and ART availability within $10 \mathrm{~km}$. Negative numbers indicate that ART was not yet available, while positive numbers indicate the number of months it was available prior to interview. Calculations based on Zambia DHS 2001 and 2007 and the Zambia Health Facilities Census. 
Figure 3: Semi-Parametric Difference-in-Difference-in-Differences Analysis of Effect of Local ART Introduction on Adult Female Height in Centimeters

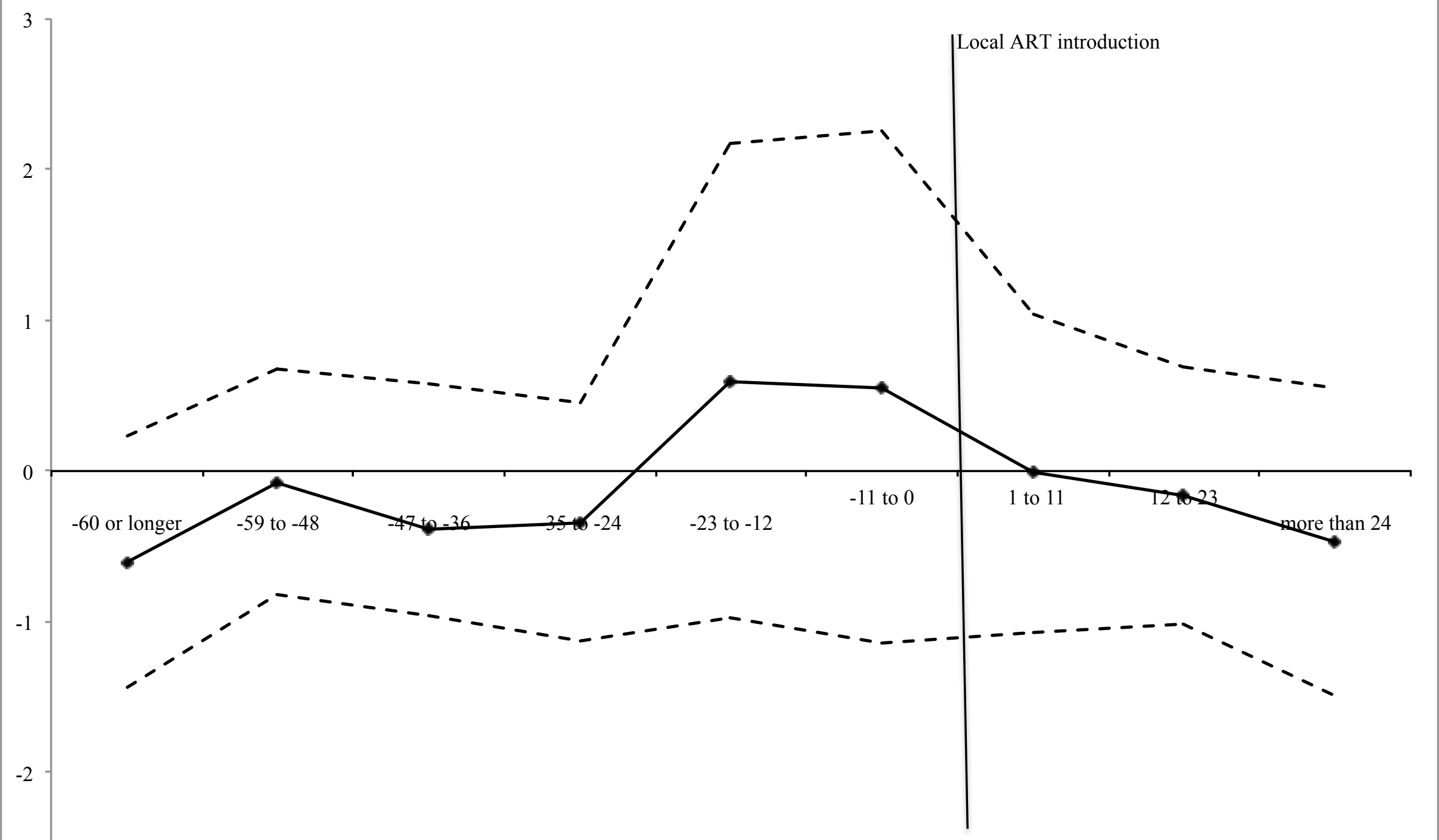

Notes: The solid line plot the estimtates of the $\beta_{\mathrm{k}}$ 's from Equation 2, using height in centimeters as the dependent variable. The dashed lines are the $95 \%$ confidence interval associated with that point estimate. 


\section{Appendix}

In order to allow for interpretation of the lower level triple-difference terms (e.g. the Year 2007 indicator variable and its interaction with likely HIV status), we estimate a restricted version of Equation (1) in which controls are not interacted with Year 2007. For example, we omit the interactions of the district fixed effects and Year 2007 $t$ and and we omit the interaction between urban residence and Year 2007. Appendix Table A1 presents the results of these restricted specifications. Across the various outcomes, the estimated effects of local ART introduction are similarly to those estimated using the unrestricted specification (i.e. as stated in Equation (1) and presented in Table 4). The lower level triple-difference terms suggest several systematic differences in anthropometrics consistent with the facts of this setting. Namely, living near ART, higher likelihood of being HIV positive, and Year 2007 are associated with higher body mass, although the differences are typically statistically insignificant. 
Table A1: Effect of Local ART on Adult Female Weight and Height, Restricted Specification

\begin{tabular}{|c|c|c|c|c|}
\hline \multirow[t]{2}{*}{ Dependent variable: } & Weight $(\mathrm{kg})$ & Height $(\mathrm{cm})$ & BMI & BMI z-score \\
\hline & (5) & $(6)$ & $(7)$ & $(8)$ \\
\hline ART ever within 10km X Year 2007 X HIV + & $\begin{array}{l}1.305^{* *} \\
(0.655)\end{array}$ & $\begin{array}{l}-0.001 \\
(0.437)\end{array}$ & $\begin{array}{l}0.487 * \\
(0.254)\end{array}$ & $\begin{array}{l}0.131 * \\
(0.068)\end{array}$ \\
\hline ART ever within $10 \mathrm{~km}$ & $\begin{array}{c}0.213 \\
(0.412)\end{array}$ & $\begin{array}{c}0.110 \\
(0.266)\end{array}$ & $\begin{array}{c}0.060 \\
(0.145)\end{array}$ & $\begin{array}{c}0.016 \\
(0.039)\end{array}$ \\
\hline Year 2007 & $\begin{array}{c}0.493 \\
(0.452)\end{array}$ & $\begin{array}{l}-0.449 \\
(0.297)\end{array}$ & $\begin{array}{c}0.367 * * \\
(0.173)\end{array}$ & $\begin{array}{c}0.099 * * \\
(0.046)\end{array}$ \\
\hline $\mathrm{HIV}+$ & $\begin{array}{c}0.242 \\
(0.306)\end{array}$ & $\begin{array}{l}-0.137 \\
(0.211)\end{array}$ & $\begin{array}{c}0.157 \\
(0.117)\end{array}$ & $\begin{array}{c}0.042 \\
(0.031)\end{array}$ \\
\hline ART ever within 10km X Year 2007 & $\begin{array}{l}-0.602 \\
(0.549)\end{array}$ & $\begin{array}{c}0.273 \\
(0.368)\end{array}$ & $\begin{array}{c}-0.294 \\
(0.203)\end{array}$ & $\begin{array}{l}-0.079 \\
(0.055)\end{array}$ \\
\hline ART ever within $10 \mathrm{~km} \mathrm{X} \mathrm{HIV} \mathrm{+}$ & $\begin{array}{l}-0.013 \\
(0.436)\end{array}$ & $\begin{array}{l}-0.368 \\
(0.297)\end{array}$ & $\begin{array}{c}0.070 \\
(0.169)\end{array}$ & $\begin{array}{c}0.019 \\
(0.045)\end{array}$ \\
\hline Year 2007 X HIV+ & $\begin{array}{c}0.419 \\
(0.403)\end{array}$ & $\begin{array}{c}0.218 \\
(0.290)\end{array}$ & $\begin{array}{c}0.082 \\
(0.159)\end{array}$ & $\begin{array}{c}0.022 \\
(0.043)\end{array}$ \\
\hline Observations & 13,684 & 13,668 & 13,662 & 13,662 \\
\hline
\end{tabular}

Notes: Data come from the 2001 and 2007 Zambia Demographic Health Surveys. "ART ever within 10km" is an indicator variable equal to one if a health clinic with 10 kilometers of the respondent offered ART at least twelve months prior to the 2007 DHS. HIV + is an indicator variable equal to one if respondent is in a demographic group with HIV prevalence above median. All specifications include the full set of controls, including lower level triple difference terms, indicated in Equation (1). Parameters estimated using ordinary least squares (OLS) regression. Standard errors are in parentheses and are clustered by Standard Enumeration Area (SEA).

*** Significant at the 1 percent level, $* *$ Significant at the 5 percent level, $*$ Significant at the 10 percent level. 